\title{
ÖTOLDALÚ TÉRMECHANIZMUS KINEMATIKAI VIZSGÁLATA
}

\section{KINEMATIC ANALYSIS OF FIVE-SIDED MECHANISM}

\author{
Popa-Müller Izolda ${ }^{1}$, Papp István ${ }^{2}$ \\ ${ }^{1}$ SAPIENTIA-Erdélyi Magyar Tudományegyetem, Müszaki és Humán Tudományok \\ Kar, Gépészmérnöki Tanszék, Románia, Koronka, Segesvári út,1/C, Fax: 0265- \\ 206211,ipmuller@ms.sapientia.ro \\ ${ }^{2}$ SAPIENTIA-Erdélyi Magyar Tudományegyetem, Müszaki és Humán Tudományok \\ Kar, Gépészmérnöki Tanszék, pappistvan1944@yahoo.com.
}

\begin{abstract}
All parts position of any spatial or planar mechanism can be clearly defined with the constraint equations. It is known that any fourth-class coupling, can be replaced with two fifth-class coupling and one plus part, being transformed in a space mechanism with one degree of freedom and is enumerated in the zero family.

This thesis contains the kinematical examination of the space mechanism and treats the position of each part. The cinematics of the coupling can be examined only with the method of DenavitHartenberg or with the constraint equations.

Keywords: constraints equations, position, centre of gravity.

\section{Összefoglalás}

A kényszeregyenletek segítségével bármely tér vagy síkban fekvő mechanizmus tagjainak pozíciója egyértelmüen meghatározható. Bármely negyedosztályú csukló két ötödfokú csuklóval és egy póttaggal helyettesíthető. Ezáltal a négyoldalú térmechanizmus egy ötoldalú térmechanizmussá alakul, amely a zérós családhoz tartozik, és amelynek szabadságfoka egy. A dolgozat az így kapott mechanizmus kinematikai vizsgálatát és a tagok helyzetének meghatározását tartalmazza. A mechanizmus kinematikai vizsgálata kényszeregyenletekkel vagy a Denavit-Hartenberg-féle módszerrel tárgyalható.
\end{abstract}

Kulcsszavak: kényszeregyenlet, pozíció, súlypont

\section{Az adatbevitel meghatározása}

Az ötoldalú mechanizmus elemei:

1. géptörzs

2. fötengely

3. hajtókar

4. kardánkereszt

5. lengökar
A programban a tagokat kapcsolási sorrend szerint 1-től 5-ig számoztuk.

A program egy kívülálló rögzített rendszerhez van felírva, amelyben a géptörzs koordinátái $X_{G 1}, Y_{G 1}, Z_{G 1}$ értékeket kaptak. A fötengely, a mechanizmust mozgató tag forgómozgást végez a $Z_{2}^{*}$ rögzített tengely körül. A vezető paraméter az Euler-szögek szerint a 


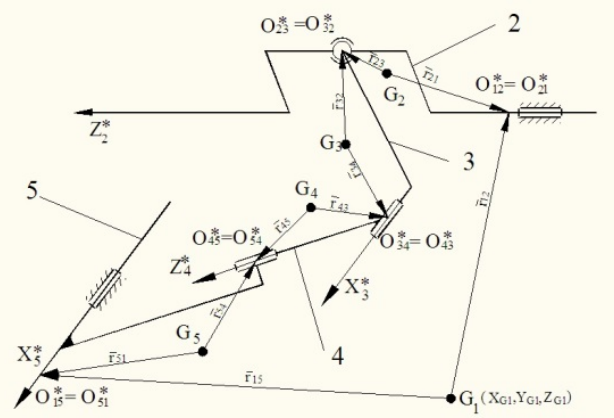

1. ábra. Ötoldalú térmechanizmus

$\psi_{2}^{*}$. A főtengely helyzetét az $\mathbf{r}_{12}$-es helyzetvektor határozza meg, amely a géptörzs súlypontját és a fötengelyen felvett gyakorlatilag jól meghatározott $O_{12}^{*}$ pontot köti össze.

Figyelembe véve, hogy az $O_{12}^{*}$ és az $O_{21}^{*}$ pontokat úgy választottuk meg, hogy egybeessenek, az $\mathbf{r}_{21}$-et úgy számítottuk ki, hogy a fötengely $G_{2}$ súlypontja gyakorlatilag meghatározott helyett foglal el.

A két tag közötti kapcsolási pontok $O_{12}^{*}=O_{21}^{*}$, a fötengely szimmetriatengelyén helyezkednek el. A $\mathbf{r}_{23}$ helyzetvektor a gömbcsukló középpontjának helyzetét határozza meg a fötengely súlypontjához viszonyítva. A hajtókart a főtengellyel egy harmadosztályú gömbcsukló kapcsolja össze. A hajtókar $G_{3}$ súlypontját az $\mathbf{r}_{32}$ és az $\mathbf{r}_{34}$ helyzetvektorok határozzák meg.

A 3-as hajtókar térmozgást végez.

A 4-es kardánkereszt a 3-as hajtókarhoz egy forgócsuklóval van kapcsolva, amely a hajtókarhoz viszonyítva $X_{3}^{*}$ tengely körül fordul el.

A két tag közös pontja az egymásra helyezett $O_{34}^{*}$ és $O_{43}^{*}$ pontok, amelyek meghatározzák az $\mathbf{r}_{34}$ és az $\mathbf{r}_{43}$ helyzetvektorok értékeit. A helyzetvektorok pedig meghatározzák mozgás közben a súlypontok helyzeteit.
$\mathrm{Az} \quad \mathbf{r}_{45}$ helyzetvektor a kardánkereszt súlypontját és a $Z_{4}^{*}$ tengelyen felvett $O_{45}^{*}$ pontot köti össze.

Az $O_{45}^{*}$ egybeesik $O_{54}^{*}$-al, amely a lengökar és a kardánkereszt elméleti mozdulatlan közös pontját képezi.

A lengőkar $G_{5}$ súlypontja egy körívet ír le az $X_{5}^{*}$ tengely körül. Az $O_{15}^{*}$ pont egybeesik az $O_{51}^{*}$-el, amely meghatározza az $X_{5}^{*}$ tengely helyzetét a $G_{1}$ súlyponthoz viszonyítva.

A vektorkontúrt az $\mathbf{r}_{15}$ helyzetvektor zárja. Az így kapott zárt vektorkontúr segítségével a kényszeregyenletek használhatóvá válnak, ezáltal meghatározhatók minden tag súlypontjának lineáris és szög koordinátái az előre megválasztott rögzített koordinátarendszerhez viszonyítva.

\section{A kényszeregyenletek meghatá- rozása}

A gép törzsét és a fötengelyt összekapcsoló forgó csukló kényszeregyenletei a következők:

$$
\begin{aligned}
& X_{G 1}+x_{12} \cdot \alpha_{11}+y_{12} \cdot \beta_{11}+z_{12} \cdot \gamma_{11}-\left(X_{G 2}+\right. \\
& +x_{21} \cdot \alpha_{12}\left(\psi_{2}, \theta_{2,}, \phi_{2}\right)+y_{21} \cdot \beta_{12}\left(\psi_{2,}, \theta_{2}, \phi_{2}\right)+ \\
& \left.+z_{21} \cdot \gamma_{12}\left(\psi_{2,}, \theta_{2}\right)\right)=0
\end{aligned}
$$

$Y_{G 1}+x_{12} \cdot \alpha_{21}+y_{12} \cdot \beta_{21}+z_{12} \cdot \gamma_{21}-\left(Y_{G 2}+\right.$

$+x_{21} \cdot \alpha_{22}\left(\psi_{2,}, \theta_{2,} \phi_{2}\right)+y_{21} \cdot \beta_{22}\left(\psi_{2}, \theta_{2}, \phi_{2}\right)+$

$\left.+z_{21} \cdot \gamma_{22}\left(\psi_{2}, \theta_{2}\right)\right)=0$

$$
\begin{aligned}
& Z_{G 1}+x_{12} \cdot \alpha_{31}+y_{12} \cdot \beta_{31}+z_{12} \cdot \gamma_{31}-\left(Z_{G 2}+\right. \\
& +x_{21} \cdot \alpha_{32}\left(\psi_{2}, \theta_{2,} \phi_{2}\right)+y_{21} \cdot \beta_{32}\left(\psi_{2}, \theta_{2}, \phi_{2}\right)+ \\
& \left.+z_{21} \cdot \gamma_{32}\left(\psi_{2}, \theta_{2}\right)\right)=0
\end{aligned}
$$


$\alpha_{12}\left(\psi_{2,}, \theta_{2}, \phi_{2}\right) \cdot \gamma_{120}+\beta_{12}\left(\psi_{2}, \theta_{2,} \phi_{2}\right) \cdot \gamma_{220}+$ $+\gamma_{12}\left(\psi_{2}, \theta_{2}\right) \cdot \gamma_{320}-b_{131}=0$

$\alpha_{32}\left(\psi_{2,}, \theta_{2}, \phi_{2}\right) \cdot \gamma_{120}+\beta_{32}\left(\psi_{2}, \theta_{2,} \phi_{2}\right) \cdot \gamma_{220}+$ $+\gamma_{32}\left(\psi_{2,} \theta_{2}\right) \cdot \gamma_{320}-b_{331}=0$

Hasonló módon írjuk fel a főtengelyt és hajtókart összekapcsoló gömbcsukló egyenleteit:

$X_{G 2}+x_{23} \cdot \alpha_{12}\left(\psi_{2}, \theta_{2}, \phi_{2}\right)+y_{23} \cdot \beta_{12}\left(\psi_{2}, \theta_{2}, \phi_{2}\right)+$ $+z_{23} \cdot \gamma_{12}\left(\psi_{2,}, \theta_{2,}\right)-\left(X_{G 3}+x_{32} \cdot \alpha_{13}\left(\psi_{3}, \theta_{3}, \phi_{3}\right)+\right.$ $\left.+y_{32} \cdot \beta_{13}\left(\psi_{3}, \theta_{3}, \phi_{3}\right)+z_{32} \cdot \gamma_{13}\left(\psi_{3}, \theta_{3}\right)\right)=0$

$Y_{G 2}+x_{23} \cdot \alpha_{22}\left(\psi_{2}, \theta_{2}, \phi_{2}\right)+y_{23} \cdot \beta_{22}\left(\psi_{2}, \theta_{2}, \phi_{2}\right)+$ $+z_{23} \cdot \gamma_{22}\left(\psi_{2,}, \theta_{2,}\right)-\left(Y_{G 3}+x_{32} \cdot \alpha_{23}\left(\psi_{3}, \theta_{3}, \phi_{3}\right)+\right.$ $\left.+y_{32} \cdot \beta_{23}\left(\psi_{3}, \theta_{3}, \phi_{3}\right)+z_{32} \cdot \gamma_{23}\left(\psi_{3}, \theta_{3}\right)\right)=0$

$Z_{G 2}+x_{23} \cdot \alpha_{32}\left(\theta_{2}, \phi_{2}\right)+y_{23} \cdot \beta_{32}\left(\theta_{2}, \phi_{2}\right)+$ $+z_{23} \cdot \gamma_{32}\left(\theta_{2}\right)-\left(Z_{G 3}+x_{32} \cdot \alpha_{33}\left(\psi_{3}, \theta_{3}, \phi_{3}\right)+\right.$ $\left.+y_{32} \cdot \beta_{33}\left(\psi_{3}, \theta_{3}, \phi_{3}\right)+z_{32} \cdot \gamma_{33}\left(\psi_{3}, \theta_{3}\right)\right)=0$

Hajtókar és kardánkereszt közötti forgó csukló egyenletei:

$X_{G 3}+x_{34} \cdot \alpha_{13}\left(\psi_{3}, \theta_{3}, \phi_{3}\right)+y_{34} \cdot \beta_{13}\left(\psi_{3}, \theta_{3}, \phi_{3}\right)+$ $+z_{34} \cdot \gamma_{13}\left(\psi_{3}, \theta_{3}\right)-\left(X_{G 4}+x_{43} \cdot \alpha_{14}\left(\psi_{4}, \theta_{4}, \phi_{4}\right)+\right.$ $\left.+y_{43} \cdot \beta_{14}\left(\psi_{4}, \theta_{4}, \phi_{4}\right)+z_{43} \cdot \gamma_{14}\left(\psi_{4}, \theta_{4}\right)\right)=0$

$Y_{G 3}+x_{34} \cdot \alpha_{23}\left(\psi_{3}, \theta_{3}, \phi_{3}\right)+y_{34} \cdot \beta_{23}\left(\psi_{3}, \theta_{3}, \phi_{3}\right)+$

$+z_{34} \cdot \gamma_{23}\left(\psi_{3}, \theta_{3}\right)-\left(Y_{G 4}+x_{43} \cdot \alpha_{24}\left(\psi_{4,} \theta_{4}, \phi_{4}\right)+\right.$ $\left.+y_{43} \cdot \beta_{24}\left(\psi_{4}, \theta_{4}, \phi_{4}\right)+z_{43} \cdot \gamma_{24}\left(\psi_{4}, \theta_{4}\right)\right)=0$

$$
\begin{aligned}
& Z_{G 3}+x_{34} \cdot \alpha_{33}\left(\theta_{3}, \phi_{3}\right)+y_{34} \cdot \beta_{33}\left(\theta_{3}, \phi_{3}\right)+ \\
& +z_{34} \cdot \gamma_{33}\left(\theta_{3}\right)-\left(Z_{G 4}+x_{43} \cdot \alpha_{34}\left(\theta_{4}, \phi_{4}\right)+\right. \\
& \left.+y_{43} \cdot \beta_{34}\left(\theta_{4}, \phi_{4}\right)+z_{43} \cdot \gamma_{34}\left(\theta_{4}\right)\right)=0
\end{aligned}
$$

$\alpha_{130} \cdot \alpha_{13}\left(\psi_{3}, \theta_{3}, \phi_{3}\right)+\beta_{13}\left(\psi_{3}, \theta_{3}, \phi_{3}\right) \cdot \alpha_{230}+$

$+\gamma_{13}\left(\psi_{3}, \theta_{3}\right) \cdot \alpha_{330}-b_{114}=0$

$\alpha_{130} \cdot \alpha_{33}\left(\theta_{3}, \phi_{3}\right)+\beta_{33}\left(\theta_{3}, \phi_{3}\right) \cdot \alpha_{230}+$

$+\gamma_{33}\left(\theta_{3}\right) \cdot \alpha_{330}-b_{314}=0$

Kardánkereszt és lengőkar közötti forgó csukló egyenletei:

$X_{G 4}+x_{45} \cdot \alpha_{14}\left(\psi_{4}, \theta_{4}, \phi_{4}\right)+y_{45} \cdot \beta_{14}\left(\psi_{4}, \theta_{4}, \phi_{4}\right)+$

$+z_{45} \cdot \gamma_{14}\left(\psi_{4}, \theta_{4}, \phi_{4}\right)-\left(X_{G 5}+x_{54} \cdot \alpha_{15}\left(\psi_{5}, \theta_{5}, \phi_{5}\right)+\right.$

$\left.+y_{54} \cdot \beta_{15}\left(\psi_{5}, \theta_{5}, \phi_{5}\right)+z_{54} \cdot \gamma_{15}\left(\psi_{5}, \theta_{5}\right)\right)=0$

$$
\begin{aligned}
& Y_{G 4}+x_{45} \cdot \alpha_{24}\left(\psi_{4}, \theta_{4}, \phi_{4}\right)+y_{45} \cdot \beta_{24}\left(\psi_{4}, \theta_{4}, \phi_{4}\right)+ \\
& +z_{45} \cdot \gamma_{24}\left(\psi_{4}, \theta_{4}, \phi_{4}\right)-\left(Y_{G 5}+x_{54} \cdot \alpha_{25}\left(\psi_{5}, \theta_{5}, \phi_{5}\right)+\right. \\
& \left.+y_{54} \cdot \beta_{25}\left(\psi_{5}, \theta_{5}, \phi_{5}\right)+z_{54} \cdot \gamma_{25}\left(\psi_{5}, \theta_{5}\right)\right)=0
\end{aligned}
$$

$$
\begin{aligned}
& Z_{G 4}+x_{45} \cdot \alpha_{34}\left(\theta_{4} \phi_{4}\right)+y_{45} \cdot \beta_{34}\left(\theta_{4}, \phi_{4}\right)+ \\
& +z_{45} \cdot \gamma_{34}\left(\theta_{4}, \phi_{4}\right)-\left(Z_{G 5}+x_{54} \cdot \alpha_{35}\left(\theta_{5}, \phi_{5}\right)+\right. \\
& \left.+y_{54} \cdot \beta_{35}\left(\theta_{5}, \phi_{5}\right)+z_{54} \cdot \gamma_{35}\left(\theta_{5}\right)\right)=0 \\
& \gamma_{140} \cdot \alpha_{14}\left(\psi_{4}, \theta_{4}, \phi_{4}\right)+\beta_{14}\left(\psi_{4}, \theta_{4}, \phi_{4}\right) \cdot \gamma_{240}+ \\
& +\gamma_{14}\left(\psi_{4}, \theta_{4}\right) \cdot \gamma_{340}-b_{135}=0 \\
& \gamma_{140} \cdot \alpha_{34}\left(\theta_{4}, \phi_{4}\right)+\beta_{34}\left(\theta_{4}, \phi_{4}\right) \cdot \gamma_{240}+ \\
& +\gamma_{34}\left(\theta_{4}\right) \cdot \gamma_{340}-b_{335}=0
\end{aligned}
$$


Végül a lengőkart a géptörzshöz kapcsoló forgó csukló egyenletei a következők:

$$
\begin{aligned}
& X_{G 5}+x_{51} \cdot \alpha_{15}\left(\psi_{5}, \theta_{5}, \phi_{5}\right)+y_{51} \cdot \beta_{15}\left(\psi_{5}, \theta_{5}, \phi_{5}\right)+ \\
& +z_{51} \cdot \gamma_{15}\left(\psi_{5}, \theta_{5}\right)-\left(X_{G 1}+x_{15} \cdot \alpha_{11}+\right. \\
& \left.+y_{15} \cdot \beta_{11}+z_{15} \cdot \gamma_{11}\right)=0 \\
& Y_{G 5}+x_{51} \cdot \alpha_{25}\left(\psi_{5}, \theta_{5}, \phi_{5}\right)+y_{51} \cdot \beta_{25}\left(\psi_{5}, \theta_{5}, \phi_{5}\right)+ \\
& +z_{51} \cdot \gamma_{25}\left(\psi_{5}, \theta_{5}\right)-\left(Y_{G 1}+x_{15} \cdot \alpha_{21}+\right. \\
& \left.+y_{15} \cdot \beta_{21}+z_{15} \cdot \gamma_{21}\right)=0 \\
& Z_{G 5}+x_{51} \cdot \alpha_{35}\left(\theta_{5}, \phi_{5}\right)+y_{51} \cdot \beta_{35}\left(\theta_{5}, \phi_{5}\right)+ \\
& +z_{51} \cdot \gamma_{35}\left(\theta_{5}\right)-\left(Z_{G 1}+x_{15} \cdot \alpha_{31}+\right. \\
& \left.+y_{15} \cdot \beta_{31}+z_{15} \cdot \gamma_{31}\right)=0
\end{aligned}
$$

$\alpha_{150} \cdot \alpha_{25}\left(\psi_{5}, \theta_{5}, \phi_{5}\right)+\beta_{25}\left(\psi_{5}, \theta_{5}, \phi_{5}\right) \cdot \alpha_{250}+$

$+\gamma_{25}\left(\psi_{5}, \theta_{5}\right) \cdot \alpha_{350}-b_{211}=0$

$\alpha_{150} \cdot \alpha_{35}\left(\theta_{5,} \phi_{5}\right)+\beta_{35}\left(\theta_{5}, \phi_{5}\right) \cdot \alpha_{250}+$

$+\gamma_{35}\left(\theta_{5}\right) \cdot \alpha_{350}-b_{311}=0$

A tagokat a kapcsolási sorrendet követve számoztuk meg.

A módszer előnye, amint látni is lehet, abban áll, hogy az ugyanazon típusú csuklóra felírt egyenletekben csak az indexek cserélödnek, míg az egyenletek formálisan változatlanok maradnak.

Mindenik kapcsolt két tagra felírt első három egyenlet a tagok súlypontjának helyzetét határozza meg az $O X Y Z$ rögzített koordináta-rendszerben, míg az utolsó két egyenlet a csuklótengelyek egybeesésének feltételét fogalmazza meg matematikailag.

A tehetetlenségi fötengelyek helyzetét a $\psi, \theta, \phi$ szögek adják meg, szintén a rögzített alaprendszerhez viszonyítva.

\section{Következtetések}

A dolgozat a kényszeregyenletek módszerének alkalmazását mutatja be. Ez egy igen hatékony, biztosan kezelhető, általános módszer, amely az eddigi ismert módszerek bármelyikét helyettesítheti.

A tudományos eredményeket hasznosítani lehet, bármely karos mechanizmus vagy robotok kinematikai vizsgálatánál. Véleményünk szerint a gépszerkezettan oktatását nagymértékben lehet a módszer bevezetésével korszerüsíteni, leginkább új laborgyakorlatok kialakításával.

A kényszeregyenletek módszerének használatával pontosan meg lehet határozni a térmechanizmusok tagjaihoz tartozó központi tehetetlenségi fótengelyek pozícióját a saját, valamint a külső rögzített koordináta rendszerhez viszonyítva.

\section{Szakirodalmi hivatkozások}

[1] Maros, D., Orlandea, N.,: Contributions to the Determination of the Equations of Motion for Multidegree of Freedom System, ASME, paper 70-Mech.-29, Ohio, USA, 1970

[2] Maros, D.,: Calcule numerice la mecanismele plane, Ed. Dacia, Cluj-Napoca, 1987

[3] Papp, I.,: Contribuţii la echilibrarea dinamică a mecanismelor spatiale., Teză de doctorat, Cluj Napoca, 2000

[4] Papp, I.: The Equations of the Constrained Screw Joints, PRASIC vol. I pag.1, 89-193, Braşov, 2002

[5] Papp I.,: Mechanizmusok elmélete, Scientia Kiadó, Kolozsvár, ISBN 978-973-1970-29-5, 2010

[6] Papp I., Popa-Müller I.: Karos mechanizmus kinematikai elemzése kényszeregyenletekkel, 1298 számú Kutatási szerződés a Sapientia Alapítvány Kutatási Programok Intézetével, 2005

[7] Papp I., Popa-Müller I.: Pozíció meghatározása kényszeregyenletek segitségével, általános transzformálás esetén, Kutatási szerződés a Sapientia Alapítvány Kutatási Programok Intézetével 2008

[8] Pelecudi, Chr.,: Teoria mecanismelor spațiale, Ed. Academiei, București, 1972 